\title{
PT x PSDB: A ATUALIZAÇÃO DO EMBATE POLÍTICO NA ELEIÇÃO PRESIDENCIAL DE 2014
}

\author{
Bruno Mello Souza ${ }^{2}$ \\ Joyce Miranda Leão Martins ${ }^{3}$
}

\begin{abstract}
Resumo
Partido da Social Democracia Brasileira (PSDB) e Partido dos Trabalhadores (PT) polarizam a disputa presidencial há 20 anos. Entretanto, verifica-se uma tendência progressiva de crescimento de candidaturas de terceira via. Utilizando dados de surveys dos Estudos Eleitorais Brasileiros (ESEB), este trabalho examina como os sujeitos que não têm votado nas candidaturas do PT e do PSDB se posicionam sobre a política brasileira e observa o comportamento político desses dois partidos dentro das propagandas partidárias de 2014. Busca-se responder: quais são as opiniões demonstradas, entre 2002 e 2010, pelos eleitores das candidaturas de terceira via nas eleições nacionais? Como a disputa política, no espaço do horário eleitoral, contribuiu para a permanência da polarização PT x PSDB na eleição presidencial de 2014? Os eleitores de terceira via apresentaram, ainda que com queda em 2006, uma elevação da satisfação com a democracia e da identificação e satisfação com os partidos; maior rejeição ao PSDB do que ao PT. Em 2014, os partidos conseguiram atualizar o embate entre eles, construindo a ideia de que Marina Silva podia ser relacionada a ambos e que a mudança simbolizada por ela era insegura.
\end{abstract}

Palavras-chave: terceira via; eleições 2014; horário eleitoral; PT; PSDB

\begin{abstract}
Partido da Social Democracia Brasileira (PSDB) and Partido dos Trabalhadores (PT) has polarized the presidential running for 20 years. Nevertheless, it can be observed a progressive growth tendency for Third Way candidatures. Using data from Estudos Eleitorais Brasileiros (ESEB) surveys, this work examines how individuals wich did not voted for PT and PSDB candidatures position themselves about the brazilian politics, and observes the political behavior of those two parties within the 2014's partidary propaganda. It seeks to answer: which are the demonstrated opinions, between 2002 and 2010, by Third Way candidature's electors in national elections? How the political dispute, at the electoral airtime space, contributed for the maintenance of PT x PSDB polarization in 2014's presidential election? The electors of a third force presented, despite decreasing at 2006, an uprising satisfaction with democracy, and identification and satisfaction with the parties; a bigger rejection to PSDB than to PT. In 2014, these parties succeed to update the debate among themselves, building the idea that Marina Silva would be relationed to them both and also that the changing which she was symbolizing would be unsafe.
\end{abstract}

Keywords: Third way; elections 2014; PT; PSDB

\section{Resumen}

Partido da Social Democracia Brasileira (PSDB) y Partido dos Trabalhadores (PT) polarizan la elección presidencial hace 20 años. Sin embargo, hay una tendencia gradual de crecimiento de candidaturas tercera vía. Utilizando datos de survey de los Estudos Eleitorais (ESEB), este trabajo examina cómo los sujetos que no han votado a los candidatos del PT y el PSDB piensan la política brasileña y observa el comportamiento político de estos dos partidos dentro de las propagandas partidarias de 2014. El objetivo es responder: ¿Cuáles son las opiniones demostradas entre 2002 y 2010, por los votantes de los candidatos de la tercera vía en las elecciones nacionales? Como la disputa política, dentro del horario eleitoral, contribuyó a la permanencia de la polarización PT x PSDB en las elecciones presidenciales de 2014? Los votantes de tercera vía mostraron, aunque con una caída

${ }^{1}$ DOI deste artigo: $10.5380 /$ recp.v6i1.39050.

${ }^{2}$ Mestre em Ciência Política pela UFRGS e doutorando em Ciência Política pela mesma instituição. E-mail: bmellosouza@yahoo.com.br

3 Mestra em Sociologia pela UFC e doutoranda em Ciência Política pela UFRGS. E-mail: joycesnitram@yahoo.com.br 
en 2006, un aumento de la satisfacción con la democracia y la identificación y satisfacción con los partidos; mayor rechazo al PSDB que al PT. En 2014, las partidos fueron capaces de actualizar la "pelea" entre ellos, construyendo la idea de que Marina Silva podría estar relacionada con los dos y que el cambio simbolizado por ella era inseguro.

Palabras clave: Tercera vía; elecciones 2014; PT; PSDB

\section{INTRODUÇÃO}

As eleições presidenciais brasileiras têm se caracterizado, ao longo dos últimos 20 anos, por uma polarização que contrapõe candidaturas do Partido da Social Democracia Brasileira (PSDB) e Partido dos Trabalhadores (PT). Entretanto, tal cenário de polarização não exclui o fato de que, desde o seu início (em 1994), verifica-se uma tendência progressiva de crescimento de candidaturas de terceira via ${ }^{4}$ nos primeiros turnos das eleições presidenciais brasileiras. E essa tendência ganhou certo impulso quando, no dia 13 de agosto de 2014, falecia em desastre aéreo Eduardo Campos, então candidato do Partido Socialista Brasileiro (PSB). Com isso, sua vice Marina Silva, que já havia ficado na terceira colocação no pleito de 2010, assumiu a cabeça da chapa e ganhou a chance de disputar a presidência mais uma vez, ameaçando estar no segundo turno e até mesmo chegar à presidência.

Nesse sentido, o crescimento das candidaturas de terceira via se coloca não só como uma possibilidade de competitividade real nas próximas eleições, como vai consolidando um tipo de eleitorado que necessita cada vez mais ser ouvido e conquistado por aqueles partidos que atualmente polarizam a disputa. Desse modo, ganha significado e relevância um estudo que proponha examinar o comportamento e algumas das predisposições do eleitor que ao longo do tempo vai buscando uma alternativa à clássica disputa entre PT e PSDB. Para isso, este trabalho utiliza dados de surveys dos Estudos Eleitorais Brasileiros (ESEB), verificando, a partir desses dados, como os sujeitos se posicionam em questões referentes a representatividade e avaliação dos partidos, satisfação com a democracia e percepções acerca de PT e PSDB.

Depois de buscar entender esse eleitor, o artigo se volta à observação do comportamento político, dentro das propagandas partidárias do PT e do PSDB, em 2014. O objetivo é verificar, por meio de uma análise das campanhas de Dilma Rousseff e Aécio Neves, no primeiro turno da eleição presidencial de 2014, as estratégias discursivas utilizadas para conter o crescimento da terceira via.

\footnotetext{
${ }^{4} \mathrm{O}$ termo terceira via é utilizado neste trabalho para designar candidaturas que se apresentam como alternativa às opções apresentadas por PT ou PSDB. O objetivo, aqui, não é realizar um debate ideológico, mas observar o comportamento de eleitores que decidiram não votar nas legendas citadas, bem como analisar as estratégias do campo político para atualizar a polarização na eleição presidencial de 2014.
} 
A importância de incorporar o horário gratuito de propaganda eleitoral (HGPE) à análise vem do próprio modelo de governo representativo atual: os partidos tiveram que adaptar seus modos de mobilização para se tornarem atraentes no âmbito de uma democracia de público, na qual a chegada e manutenção no poder se dá, primordialmente, através da disputa de imagens ${ }^{5}$ (MANIN, 1995), que são fundamentais em embates majoritários. A disputa imagética da política ocorre tendo a mídia, em especial a TV e a internet, como intermediárias entre candidatos e população ${ }^{6}$. O HGPE - espaço de uso exclusivo do campo político, dentro da rádio e da TV - é palco principal das estratégias discursivas de cada campanha. Dele também saem vídeos e argumentos que a militância compartilha nas redes sociais. Nas democracias de público, as eleições ocorrem com o objetivo de formar a opinião (CHAMPAGNE, 1998) ou reforçar esta, que costuma ser fluida.

Combinando pesquisas de opinião, dados eleitorais e análise do discurso do primeiro turno da eleição presidencial no HGPE televisivo, este artigo busca responder: quais são as opiniões demonstradas, entre 2002 e 2010, pelos eleitores das candidaturas de terceira via nas eleições nacionais? Como a disputa política, no espaço do horário eleitoral, contribuiu para a permanência da polarização PT x PSDB na eleição presidencial de 2014? Em outras palavras, como a propaganda pode ter ajudado na atualização da polarização entre PT e PSDB, em momento em que uma terceira via parecia ganhar força? A próxima seção deste artigo se destina a examinar as opiniões e percepções dos eleitores de terceira via em relação a aspectos que dizem respeito à democracia brasileira e aos dois partidos que polarizam a disputa presidencial nos últimos anos. Em seguida, vai se passar à análise das campanhas do PT e do PSDB em 2014 e como os discursos colaboraram para reatualizar a polarização costumeira. Por fim, apresenta-se as considerações finais acerca do que se demonstra ao longo do artigo.

\section{PERCEPÇÕES E OPINIÕES DOS ELEITORES DE TERCEIRA VIA NO BRASIL (2002-2010)}

Tendo se iniciado em 1994, quando o PSDB chegou ao executivo federal, a polarização entre este e o P'T se mantém consistente ao longo de 20 anos. Durante o período, não só um dos dois partidos saíram vitoriosos das eleições, como invariavelmente a segunda

\footnotetext{
${ }^{5}$ Fala-se na imagem não apenas em sua conotação visual, mas também abstrata, quando referida à personalidade que os candidatos buscam mostrar que possuem.

${ }^{6}$ No Brasil, foi a eleição de Collor, em 1989, que mostrou a fragilidade do sistema partidário como único intermediário entre candidatos e população.
} 
colocação ficou com seu antagonista. Mais do que isso, os dois partidos concentraram no mínimo 2/3 dos votos para presidente em todos os pleitos (CERVI, 2014).

Em 1994, apoiado sobre o Plano Real, que serviu para estabilizar o processo inflacionário brasileiro (ALMEIDA, 1999), Fernando Henrique Cardoso (FHC) conseguiu aglutinar as diferentes elites políticas e econômicas em torno de sua candidatura e vencer Lula (GUGLIANO e JEREZ, 1996). Em 1998, FHC logrou reeleger-se superando o candidato petista pela segunda vez em um cenário de crise financeira internacional, colocando a si e a sua equipe econômica como os mais preparados para enfrentar as intempéries características desse tipo de panorama (MIGUEL, 1999). Já em 2002, o PT conquista a presidência pela primeira vez, em um contexto marcado pelo agravamento da crise internacional. Com o mote da esperança que vence o medo, e a apresentação de um Lula palatável às elites, a vitória petista foi quase inevitável.

No ano de 2006, pautado por suas políticas sociais, Lula se descola do PT, envolvido no caso do mensalão ${ }^{7}$, e coloca-se como o "pai dos pobres", aproveitando, simultaneamente, o bom momento macroeconômico vivido pelo país (BAQUERO, 2007). Em 2010, Dilma Rousseff, do PT, tratou de vincular sua imagem à de Lula, de enorme aprovação, enquanto o PSDB não conseguiu ocupar de forma eficaz o espaço discursivo de oposição (MARTINS, 2012). Em 2014, o PT conquistou mais uma vitória com Dilma, superando Aécio Neves no segundo turno de uma campanha acirrada, marcada pela ascensão e queda de Marina Silva. Pela sexta eleição consecutiva, PT e PSDB polarizaram a eleição.

Tabela 1 - Dois primeiros colocados nas eleições presidenciais (1994-2014)

\begin{tabular}{|c|c|c|c|c|}
\hline & \multicolumn{2}{|c|}{ Eleito } & \multicolumn{2}{|c|}{ Segundo colocado } \\
\hline 1994 & $\mathrm{FHC}$ & psos & Lula & \\
\hline 1998 & $\mathrm{FHC}$ & $P=$ & Lula & \\
\hline 2002 & Lula & & Serra & Psos \\
\hline 2006 & Lula & & Alckmin & $P{ }^{2}$ \\
\hline 2010 & Dilma & & Serra & PsDB \\
\hline 2014 & Dilma & & Aécio & $P$ \\
\hline
\end{tabular}

Fonte: Tribunal Superior Eleitoral.

\footnotetext{
${ }^{7}$ Este escândalo foi chamado de "mensalão", e foi denunciado pelo então deputado federal pelo Rio de Janeiro, Roberto Jefferson, do PTB. Consistia, a grosso modo, na compra de votos dos parlamentares, em troca de apoio às iniciativas do governo federal junto ao Congresso.
} 
Cabe sublinhar: mesmo considerando a permanência do cenário de polarização entre os dois partidos, as eleições de 2014 sinalizaram, também, uma tendência de crescimento das candidaturas de terceira via que se verificou ao longo dos últimos 20 anos.

Gráfico 1 - Evolução das candidaturas de terceira via no Brasil (1994-2014) (\%)

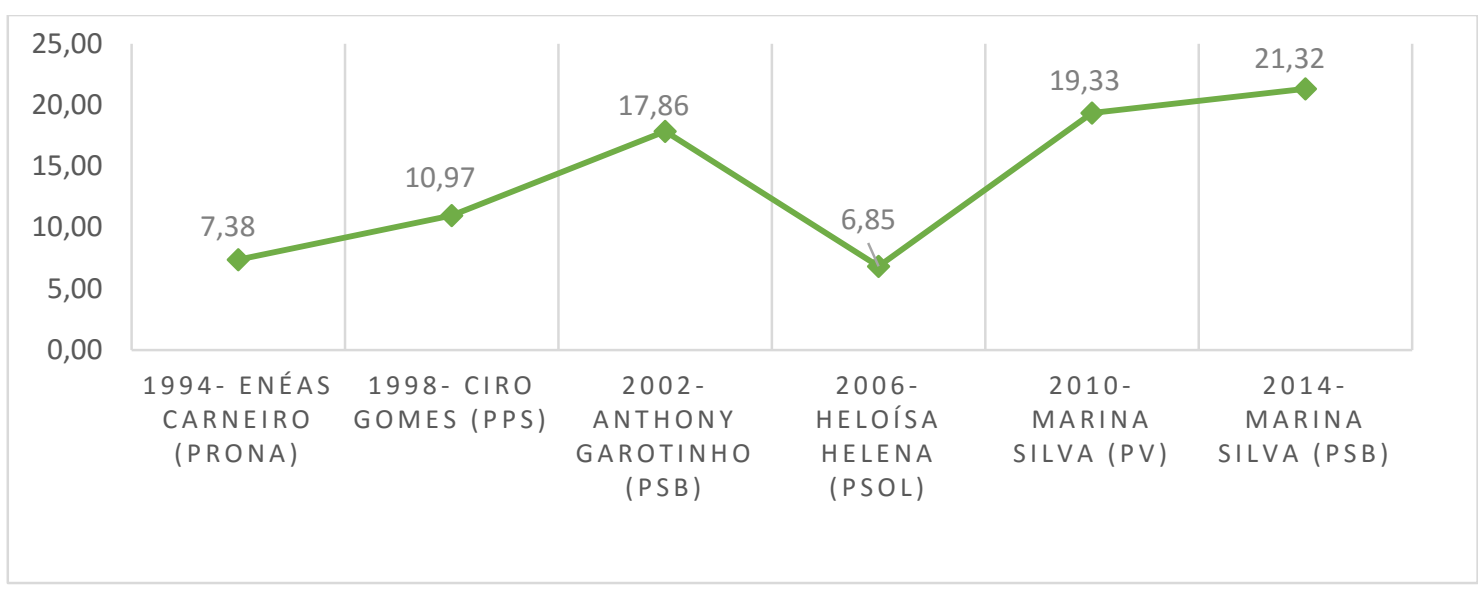

Fonte: Tribunal Superior Eleitoral.

O crescimento percentual dos eleitores de terceira via instiga uma investigação do que, afinal, esses cidadãos pensam sobre a política brasileira. Os dados examinados são dos Estudos Eleitorais Brasileiros, do Centro de Estudos de Opinião Pública (CESOP), da Universidade Estadual de Campinas (UNICAMP) dos anos 2002, 2006 e $2010^{8}$. Iniciamos a análise com uma questão que remete a uma percepção mais ampla a respeito da democracia no país.

Gráfico 2 - Satisfação com a democracia no país (\%)

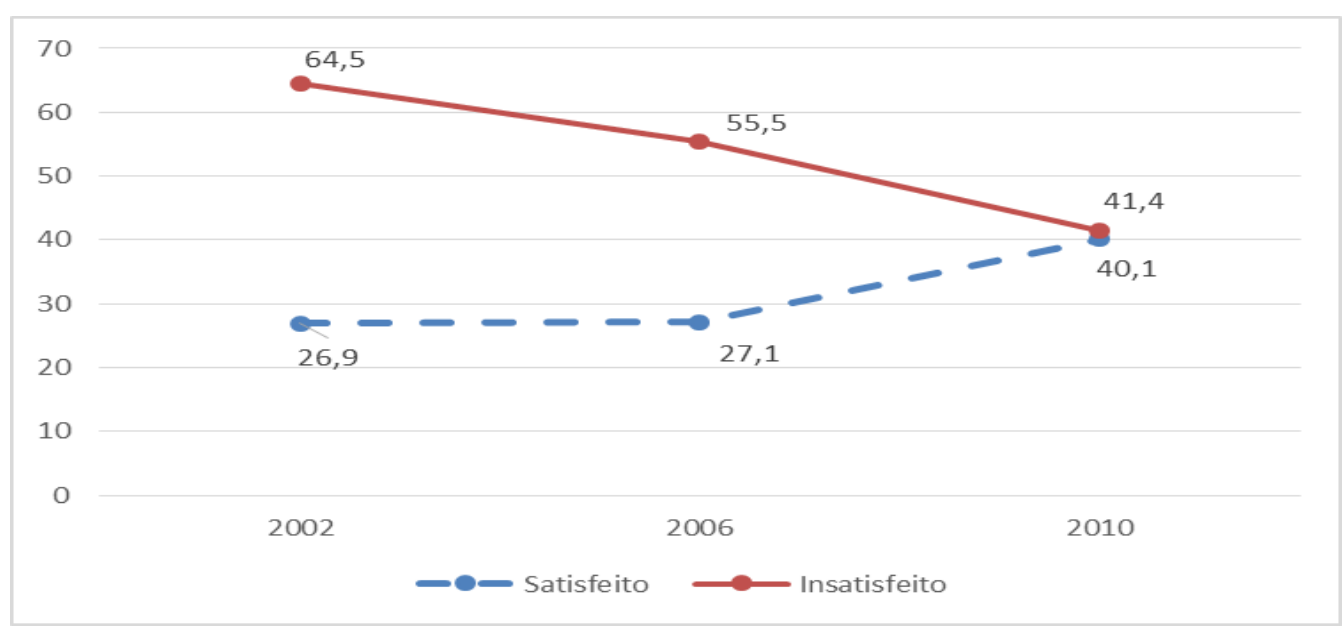

Fonte: ESEB.

$\mathrm{n}(2002)=263, \mathrm{n}(2006)=39, \mathrm{n}(2010)=328$

8 Amostra de 2002: 2513; de 2006: 1000; e de 2010: 2000. 
* Em "satisfeito" agregou-se "satisfeito" e "muito satisfeito"; em "insatisfeito" agregou-se "nada satisfeito" e "pouco satisfeito".

De um modo geral, tem havido um aumento significativo da satisfação dos eleitores de terceira via para com a democracia no Brasil. Entre 2002 e 2006, há uma estabilidade entre os que afirmavam sua satisfação flutuando em $27 \%$, e aumentando substancialmente em 2010, quando tal percentual alcança 40\% dos entrevistados. A queda progressiva dos que afirmam estar insatisfeitos, ou seja, a dimensão negativa da satisfação apresenta uma notícia ainda mais auspiciosa para a democracia do ponto de vista da opinião pública desse tipo de eleitor. Todavia, os movimentos de junho de 2013 podem ter causado um impacto de reversão nesse cenário, devido a um discurso de certa repulsa aos partidos. Vistas as dimensões da satisfação com a democracia, agora cabe verificar o tipo de relação que esses eleitores estabelecem para com as instituições que são - ou deveriam ser - as representantes políticas por excelência dos cidadãos, os partidos políticos.

Gráfico 3 - Algum partido representa sua forma de pensar? (\%)

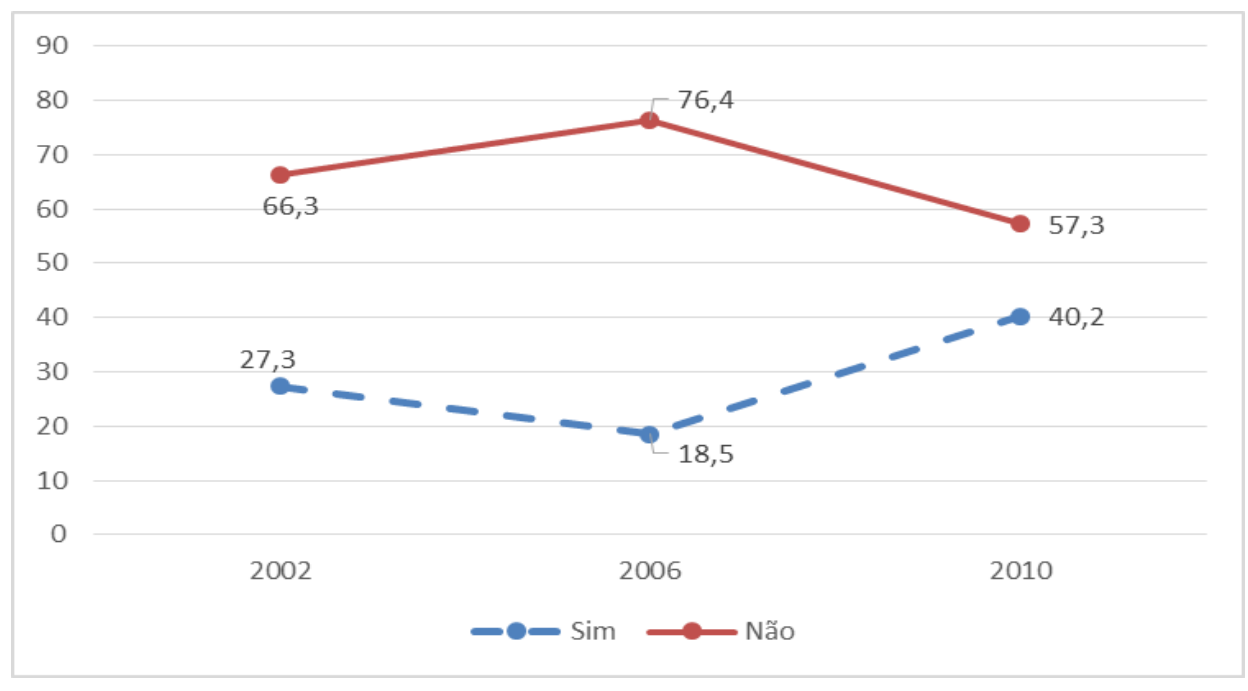

Fonte: ESEB.

$\mathrm{n}(2002)=263, \mathrm{n}(2006)=39, \mathrm{n}(2010)=328$

Chama a atenção o fato de que a identificação partidária sofreu variações importantes ao longo do período verificado. Entre 2002 e 2006 ela teve uma queda de quase 10\%, recordando uma vez mais aspectos como o mensalão e o tipo de candidatura de protesto que representava Heloísa Helena no segundo ponto temporal. Após isso, em 2010, o índice de identificação dos simpatizantes de candidatos de terceira via - neste caso, de Marina Silva -, 
praticamente dobra, alcançando os 40\%. O gráfico seguinte nos permite um passo além, observando como esses eleitores avaliam na prática os partidos políticos existentes no país.

Gráfico 4 - Avaliação dos partidos políticos (\%)

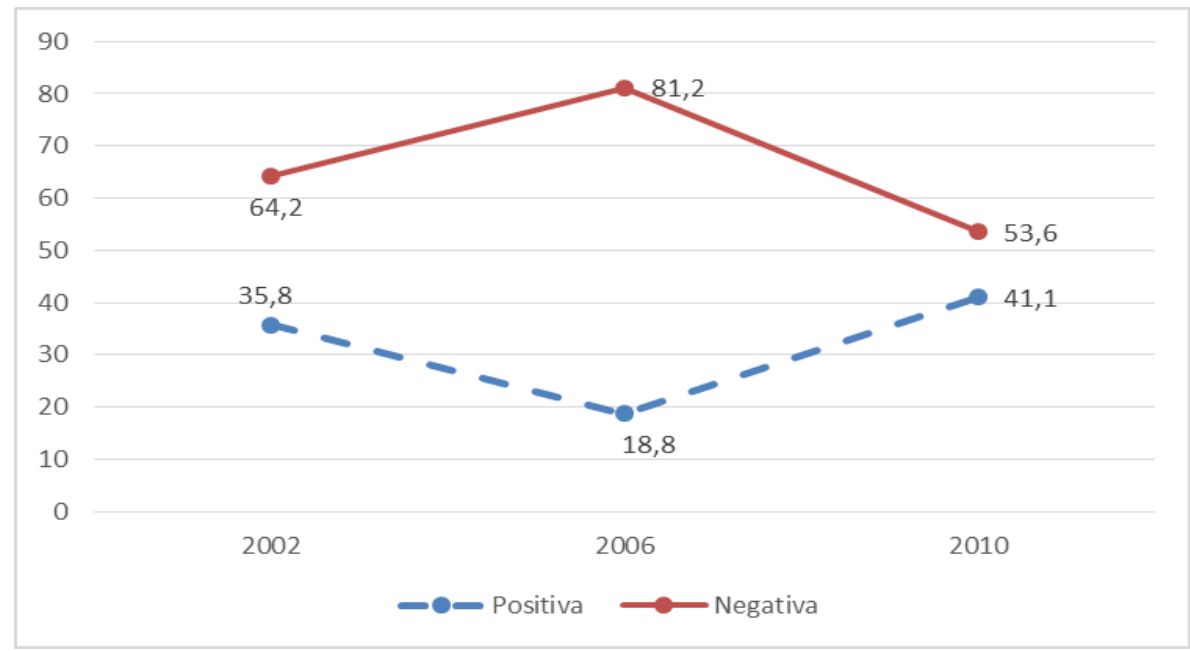

Fonte: ESEB.

$\mathrm{n}(2002)=263, \mathrm{n}(2006)=39, \mathrm{n}(2010)=328$

*Em "positiva" agregou-se "ótima", "boa" e "regular para boa"; em "negativa" agregou-se "péssima", "ruim" e "regular para ruim".

Uma vez mais, é possível perceber com clareza que o contexto eleitoral de 2006 fora problemático em termos institucionais no Brasil. Ali, ocorre o pico de avaliação negativa dos partidos (mais de 80\% dos eleitores de Heloísa Helena, na época). E, repetindo algumas das tendências anteriormente verificadas, em 2010 se nota uma certa recuperação do âmbito institucional brasileiro junto aos eleitores de terceira via, ainda que a avaliação negativa prepondere em todos os pontos de tempo sobre a avaliação positiva. E no que diz respeito aos partidos hegemônicos, PT e PSDB, qual é a opinião desses eleitores? Começamos com a opinião que esses sujeitos possuem sobre o PSDB. 
Gráfico 5 - Opinião sobre o PSDB (\%)

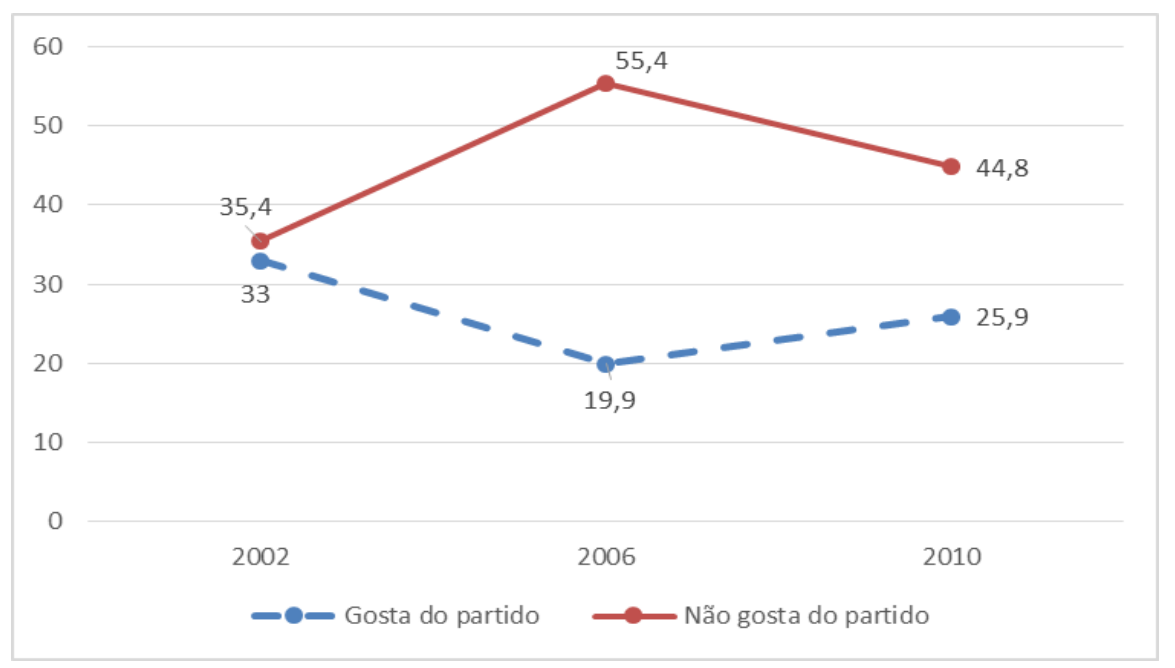

Fonte: ESEB.

$\mathrm{n}(2002)=263, \mathrm{n}(2006)=39, \mathrm{n}(2010)=328$

* A questão original possuía uma escala que partia de "não gosta do partido", passava por valores de 1 a 9, e chegava a "gosta muito do partido". Assim, de "não gosta do partido" até o valor 4, agregou-se como "não gosta do partido"; do valor 6 até "gosta muito do partido", agregou-se como "gosta do partido". O valor 5 , que era exatamente o valor do meio, não foi agregado a lado nenhum.

É possível perceber que em 2002, os eleitores de Anthony Garotinho eram os que possuíam maior simpatia pelo PSDB. Em 2006, como seria de se esperar, o desprestígio desse partido junto aos simpatizantes da candidatura do PSOL, chega ao seu ápice, com 55\% dos eleitores afirmando não gostarem do PSDB. Em 2010, a rejeição ainda é bastante considerável junto aos então eleitores de Marina Silva, porém decresce razoavelmente. No próximo gráfico, examinamos a opinião que esses cidadãos têm ao longo do tempo em relação ao PT.

Gráfico 6 - Opinião sobre o PT $(\%)$

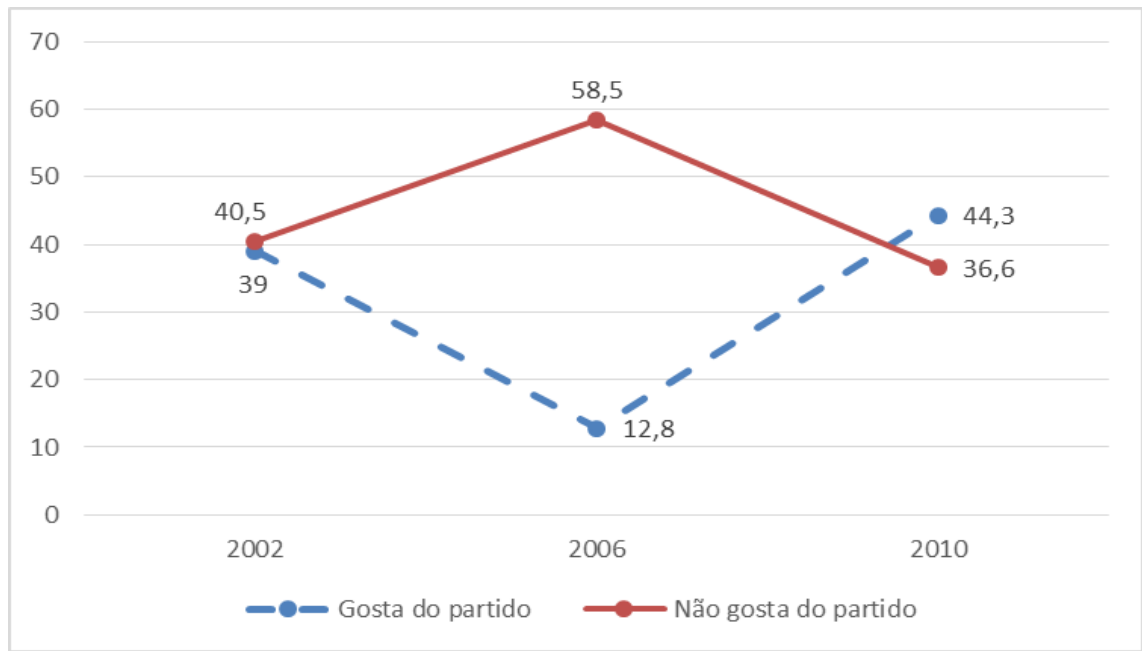

Fonte: ESEB. 
$\mathrm{n}(2002)=263, \mathrm{n}(2006)=39, \mathrm{n}(2010)=328$

* A questão original possuía uma escala que partia de "não gosta do partido", passava por valores de 1 a 9, e chegava a "gosta muito do partido". Assim, de "não gosta do partido" até o valor 4, agregou-se como "não gosta do partido"; do valor 6 até "gosta muito do partido", agregou-se como "gosta do partido". O valor 5 , que era exatamente o valor do meio, não foi agregado a lado nenhum.

Novamente, como já foi possível notar, no que tange ao PSDB, percebe-se um equilíbrio em relação ao eleitorado da terceira via no ano de 2002 e um aumento muito significativo da rejeição ao PT em 2006, rejeição maior inclusive que a que o mesmo eleitorado do PSOL tinha em relação ao PSDB. Em 2010, entretanto, a simpatia em relação ao PT aumenta junto ao eleitorado de terceira via, sendo que a maioria dos simpatizantes de Marina Silva na época respondeu que gostavam do Partido dos Trabalhadores. Assim, o espaço de diálogo com esses eleitores alternativos aos dois partidos principais parecia ser, ao menos até 2010, maior para os petistas. Todavia, o cenário de 2014 apresentou fatos que podem reverter essa tendência em análises futuras, uma vez que Marina Silva manifestou apoio ao PSDB de Aécio Neves no segundo turno. Ao mesmo tempo, parece haver um crescimento do sentimento antipetista em parcelas significativas da população, o que pode aumentar consideravelmente a margem do partido tucano para se aproximar desse eleitorado crescente nos próximos movimentos do jogo eleitoral brasileiro.

\section{ATUALIZAÇÃo DA POLARIZAÇÃo ENTRE PT E PSDB NO ÂMBITO DISCURSIVO EM 2014}

Antes de partir para a análise das propagandas partidárias, vale falar um pouco sobre a análise do discurso e o porquê da escolha do método. Em primeiro lugar, é importante ressaltar que é no discurso que as práticas sociais são materializadas (PINTO, 1989). Nesse sentido, o discurso é uma entre tantas práticas da política. Como lembra Charaudeau (2006), não existe política sem discurso. Este é constitutivo daquela. A linguagem orienta e dá sentido à ação. A opção de observar o discurso, em vez do conteúdo, ocorreu porque, em contexto em que todos os candidatos tentariam se apropriar do sentimento de mudança (captado nas pesquisas de opinião e visto no junho de 2013 como sendo forte na população brasileira), importava perceber os distintos significados que "mudança" ganharia, de que formas os candidatos tentariam mobilizar esse sentimento para tentar convencer o eleitor.

Os analistas do discurso (ORLANDI, 2012; MAINGUENEAU, 2005) costumam dividir as falas em momentos passíveis de serem observados objetivamente. Para este artigo, são importantes as noções de: (1) Ethos: construção da imagem de si; (2) Lugar de fala: 
relacionado à posição dentro de um campo ${ }^{9}$ e ao posicionamento discursivo do enunciador; (3) Condições sociais de produção: refere-se a condições que permitem um discurso emergir e conseguir adesão em determinado contexto; (4) Interdiscurso: seria o discurso que está dentro de outro, que o permite ressignificá-lo e atualizá-lo; (5) Formações discursivas: série de discursos que permitem a formação de outros, estão ligadas às formações ideológicas (visões de mundo).

Para a análise do discurso dos programas do horário eleitoral, toda a propaganda partidária foi observada. Porém, aqui foram selecionados, para análise mais detalhada, apenas os programas de Aécio Neves e Dilma Rousseff, exibidos no período noturno ${ }^{10}$, no chamado "horário nobre da TV", quando a audiência costuma ser maior. Mais do que convencer o eleitor de que merecia seu voto, PT e PSDB tinham um novo desafio em 2014: convencer a população de que Marina Silva não era uma boa candidata. Só assim, Dilma e Aécio poderiam ter chances de vitória. As alianças de Dilma davam a ela 11 minutos e 24 segundo no HGPE, enquanto Aécio tinha apenas 4 minutos e 35 segundos. A seguir, uma análise do comportamento de ambos os candidatos no horário eleitoral.

\subsection{DILMA ROUSSEFF: A MUDANÇA SOU EU}

Dilma precisava se defender dos ataques e esclarecer por que seu o governo não foi melhor, explicando também os escândalos de corrupção. Tinha como vantagem: estar no lugar de fala da situação, de onde realizações não são promessas, mas conquistas passíveis de serem mostradas. Além disso, ela tinha o dobro do tempo de Marina e Aécio juntos.

Os primeiros programas da candidata foram destinados a uma defesa prévia dos ataques aos adversários. Ela era uma grande mulher com a experiência e capacidade para conduzir o Brasil em meio a uma crise internacional, a qual foi a responsável pelo fato de o país não ter crescido ainda mais. O Brasil atual é contrastado com o Brasil do passado, um lugar de poucas oportunidades, apenas para privilegiados. Lula aparece sempre ao final das propagandas, sem os ternos chiques de quando era presidente, mas de branco, com a serenidade de quem tem experiência e sabedoria sobre o que fala. No dia 26 de agosto, ele explica que a própria escolha de Dilma, para ser sua sucessora, foi pelo fato de ela representar uma mudança em relação aos políticos tradicionais (fala que servia ao mesmo tempo para agradar os manifestantes do junho de 2013 e para alertar aos eleitores que pensassem em votar na Marina por ela ser a "nova política"):

\footnotetext{
${ }^{9}$ Sobre o conceito de campo, ver Bourdieu (1989).

10 Os programas de Marina Silva também foram observados, porque as estratégias da campanha de Dilma e Aécio eram pensadas no sentido de desconstruir o que Marina apresentava.
} 


\begin{abstract}
Meus amigos e minhas amigas, hoje, tudo que é candidato diz que é o novo. [...] Uma coisa eu posso garantir: Dilma é o que tem de mais novo, verdadeiramente novo na política brasileira. [...] Esse é um dos principais motivos porque lutei para que ela me sucedesse. Eu reconheci na Dilma alguém de fora do mundinho limitado da política.
\end{abstract}

Os programas seguintes são dedicados a ações do governo Dilma. Até o momento, as críticas à candidata da terceira via eram veladas e a propaganda do PT insistia em dizer claramente apenas que o país já fora pior. Como a polarização com o PSDB não era o que assustava até então, em setembro entra em vigor a estratégia para diminuir o avanço de Marina nas pesquisas de intenção de voto (até ali, Marina ameaçava a reeleição de Dilma).

O programa do dia 02 de setembro é aberto com falas da Dilma no debate (promovido por Uol, Folha e Joven Pan), com a candidata questionando promessas de Marina: "o montante prometido pela senhora em todas essas promessas equivale a quase tudo que se gasta em Saúde, Educação [...] o que ocorre, quando se é presidente da República, é que se tem que explicar como vai ser feito". A candidata-presidente também questionou Marina sobre o fato de o programa de governo desta (de 242 páginas, de acordo com Dilma, só ter uma linha sobre o pré-sal) e sobre os jornais estarem afirmando que ela disse que a posse do pré-sal é feita de maneira errada. O narrador em off afirma: "ser contra o pré-sal é ser contra o futuro do país". Voltando-se ao tema da corrupção, propostas de Dilma, para o combate das práticas corruptas, são apresentadas. No final, mais uma vez o ataque à Marina. O debate do início é mostrado novamente, com Dilma afirmando que sem apoio no Congresso Nacional “não é possível assegurar um governo estável, um governo sem crises institucionais". Da fala da candidata, passa-se ao apresentador da propaganda que reforça o que havia sido dito: "em uma democracia, ninguém governa sem partidos. Ninguém governa sozinho". O narrador em off termina a explicação:

\footnotetext{
A base de apoio de Marina Silva tem hoje 33 deputados. Sabe de quantos ela precisaria para aprovar um simples projeto de lei? No mínimo, uns 129. E uma emenda constitucional? 308. Como é que você acha que ela vai conseguir esse apoio sem fazer acordos? E será que ela quer? Será que ela tem jeito para negociar?
}

A fala termina comparando Marina a Jânio Quadros e Collor de Mello, candidato que estava apoiando o PT: "Duas vezes na nossa história o Brasil elegeu salvadores da pátria, chefes do partido do "Eu sozinho" [aparece imagem da renúncia de Jânio, em um jornal]. E a gente sabe como isso acabou" [foto do anúncio do impeachment de Collor, na Folha de São Paulo]. O narrador convida o eleitor a "acordar": "Sonhar é bom, mas eleição é hora de botar o pé no chão e voltar à realidade". 
O programa do dia 04 de setembro é destinado à Educação, com beneficiários de programas sociais de Dilma (no ensino fundamental; técnico, universitário). Ao final da propaganda, novo ataque à Marina, vindo de uma apresentadora:

\begin{abstract}
Você viu: Dilma tem feito muito pela Educação e vai fazer muito mais, porque tem novas propostas e garantiu, por lei, que $75 \%$ das riquezas que serão produzidas pelo pré-sal vão ser investidas, obrigatoriamente, em Educação [na tela aparece: 1,35 trilhão para Saúde e Educação]. É assim que faz uma presidente que entende e defende o Brasil, muito diferente de "certa" candidata que não quer dar prioridade à exploração do pré-sal. Isso seria sacrificar o futuro da Educação e o futuro do Brasil. É hora do Brasil todo se unir para defender o pré-sal, porque ele é o futuro do Brasil.
\end{abstract}

O narrador em off resume a mensagem: "Ser contra o pré-sal é ser contra o futuro do Brasil". No dia 06 de setembro, aberto com o hino nacional ao fundo (por causa da Independência do país, comemorada no dia 07), é a própria Dilma quem, diretamente, ataca Marina:

A independência é uma conquista que precisa ser fortalecida todos os dias. Cada momento na vida do Brasil exige de nós um esforço diferente. [...] Nesse exato momento, é a defesa do pré-sal. Essa imensa riqueza, que é o nosso passaporte para o futuro. Essa luta torna-se particularmente importante porque surgem vocês que ameaçam esta grande riqueza nacional. A candidata Marina Silva é uma delas, pois tem defendido o fim da prioridade ao pré-sal. [...] Isso significaria abandonar ou desacelerar a exploração dessa imensa fonte de riqueza, com consequências terríveis para o desenvolvimento do Brasil.

Durante o programa, o narrador em off repete a mensagem "ser contra o pré-sal é ser contra o futuro do Brasil" e apresentadores explicam o que significa o pré-sal (ou porque Marina Silva poderia ser um grande perigo): "isso significaria desprezar a maior oportunidade de desenvolvimento que já tivemos em toda a nossa história". Enquanto os apresentadores falavam, apareciam manchetes de jornais, dizendo que Marina deixaria o pré-sal em segundo plano.

Em estratégia semelhante a apresentada por Aécio, em seu programa do dia 04 de setembro (olhar tópico seguinte, que fala sobre o presidenciável), Dilma, no dia 06, volta a criticar Marina: "Ela tem propostas na área econômica que repetem alguns erros dos governos tucanos, que trouxeram desemprego e arrocho salarial no passado [..] Chega a dar passos ainda mais atrás do que os tucanos". A similitude entre os discursos de Aécio e Dilma: enquanto Aécio relacionou Marina ao PT, Dilma a ligou ao PSDB, afirmando que Marina tinha se revelado uma candidata com visões profundamente equivocadas. Ao aproximar Marina dos partidos adversários, a estratégia de PT e PSDB era clara: afirmar que Marina não representava o fim da polarização, mas uma continuação insegura de PT ou PSDB. A ideia petista de falar no pré-sal (e insistir que ele era ameaçado por Marina) repetiu-se nos 
programas seguintes, com Lula chegando a dizer que mergulharia no fundo do mar, se fosse preciso, para pegar o pré-sal para Dilma.

No programa do dia 09 de setembro, destinado à corrupção, Marina também não escapa de críticas. A apresentadora afirma que decisões econômicas erradas são uma forma de desviar o direito da nação para poucos. A autonomia do Banco Central, proposta de Marina, seria isso. Privilegiar o interesse de poucos, em prejuízo para os que mais precisam.

As propagandas seguintes são voltadas para propostas de Dilma, como a Segurança Integrada entre os estados da federação, a Banda Larga para Todos, o programa Mais Especialidades (que complementaria o Mais Médicos). No dia 13 de setembro, Dilma explica por que o Brasil que ela quer é o mesmo que os eleitores desejam: "O Brasil que queremos é este que inova, que tem compromisso com uma Educação e uma Saúde de qualidade. [...] Um Brasil que está sendo construído com muito trabalho e não quer voltar para trás nem dar um salto no escuro". A mensagem era sempre de que "não se está partindo do zero, mas da boa experiência".

Depois de a propaganda apresentar propostas para a melhoria de estradas e do transporte público, Dilma aparece conversando com lideranças de movimentos sociais que estiveram no junho de 2013. Eles afirmam que as manifestações não foram uma negação da política nem endereçadas a alguém em específico, o que estava em xeque era o próprio sistema político, diz o secretário nacional de juventude da CUT. A representante da juventude do MST diz que conseguiram unificar os movimentos sociais em torno da reforma do sistema político.

A reforma política era uma proposta da própria candidata petista. Nesse sentido, há clara disputa para impor o significado das manifestações de junho, que foram plurais e contaram com parcelas de cidadãos que desejavam, sim, que o caráter dos protestos fosse apartidário. Mas como Marina aparecia como a canalizadora do sentimento de junho de 2013, era importante mostrar que muitos que estavam lá não protestavam contra o governo.

Os programas seguintes foram destinados às conquistas dos mandatos do PT, como a saída do Brasil do Mapa da Fome da ONU, sempre reforçando a ideia de que o voto em Marina seria um salto no escuro, símbolo da insegurança. Escolher Aécio, por sua vez, representava um retrocesso. A ideia geral era expressa no jingle, exibido em 18 de setembro: "Não deixa a mudança parar, não deixe parar de mudar".

Depois que Marina caiu drasticamente nas pesquisas de intenção de voto, o que aconteceu em meados de setembro, a propaganda do PT diminuiu os ataques à candidata, enfatizando os feitos dos governos Lula e Dilma. Sobre esta, foram frequentes as propostas 
de combate à corrupção, de melhoria para a mobilidade urbana, do programa Mais Especialidades. Exceção ocorreu quando, no dia 30 de setembro, Dilma apresentou o que ela chamou de contradições de Marina Silva. Porém, também sobraram críticas para Aécio que, igualmente, foi mostrado como contraditório. Afirmava Dilma que uma hora ele dizia que a Petrobrás não seria privatizada e, em outra, mudava de ideia. O que o programa procurava ratificar é que, qualquer um dos dois que fosse ao segundo turno, era uma escolha de voto ruim.

No último programa de Dilma, o tema da mudança voltou mais forte, com o lema: "governo novo, ideias novas". Depois de pessoas do povo aparecem, narrando promessas de um novo mandato, quem vem à cena é Lula, que já havia aparecido de forma constante, no HGPE, para ser o fiador da candidata. O ex-presidente, ao perguntar à Dilma, pergunta implicitamente à nação: "qual país que tem uma perspectiva de futuro mais extraordinária que o Brasil"? Ao que Dilma responde que os seus opositores não reconhecem a importância de sua pátria. Logo depois, a candidata-presidente pede reflexão aos eleitores:

\footnotetext{
Nesse momento, todo mundo deve se perguntar: quem tem mais capacidade e experiência para manter o que já conquistamos, corrigir o que for preciso e fazer ainda mais? Quem tem força e apoio político para fazer as reformas que o Brasil exige? [...] Eu peço, humildemente, o seu voto, pedindo que você reflita sobre todas essas questões. Tenho certeza que, ao responder essas perguntas, você vai fazer a melhor escolha.
}

O efeito de sentido que se pretende gerar é: quem pensa, vota na Dilma; quem não é ingrato, vota na mãe-presidente, pois ela está com o povo. O narrador em off é quem finaliza o programa: "ninguém pode nos impedir de ir ainda mais longe..." É como se dissessem: "os adversários da presidente não são inimigos só dela, mas de vocês também".

\subsection{AÉCIO NEVES: A OPOSIÇÃO CONFIÁVEL}

Aécio vinha com a vantagem de estar no lugar de fala do partido de oposição tradicional ao PT: por si só, já representava uma mudança. Diferente de antigos candidatos à presidência pelo $\mathrm{PSDB}^{11}$, ele não fugia a este lugar e afirmava se apresentar como candidato porque o Brasil não estava bem. Apesar de ter melhorado nos últimos anos, o país, para Aécio, piorara no governo Dilma e não por culpa do povo, mas do comando da nação.

Em seu primeiro programa, Aécio aparece falando como um estadista, enquanto o povo o escuta, de longe, através da televisão. Se Dilma era herdeira do legado de Lula e

\footnotetext{
11 Ver: Almeida (2004).
} 
Marina da missão de levar adiante as ideias de Campos ${ }^{12}$, Aécio também tinha um "padrinho" valoroso, seu próprio avô, Tancredo Neves. Eleito indiretamente à presidência da República, Tancredo morreu vítima de uma diverticulite (inflamação no intestino), sem poder assumir o cargo. Sua morte emocionou o país que "parou" para ver, na TV, o ritual de despedida do político. Agora, décadas depois, o Brasil teria a oportunidade de ter outro Neves na presidência.

Aécio se mostrava como um político responsável, casado e com "coragem para fazer diferente". Diz que quando assumiu Minas a situação era gravíssima, porém, de acordo com seu HGPE, saiu do estado com 92\% de aprovação (programa exibido no dia 21 de agosto).

Com o amparo da história do avô, o governo em Minas e a legitimidade de exigir mudanças (legitimidade por falar de acordo com os anseios da população), Aécio tinha o desafio de convencer que ele era a melhor mudança e não Marina, que ameaçava a polarização com o PT. Para convencer o eleitor, além de explorar as ações como governador de Minas, tentou se aproximar do eleitorado jovem, colocando vários para falar com ele e expor seus problemas, durante o horário eleitoral do dia 26 de agosto. Nesse programa, expõe suas ideias para essa faixa do eleitorado, falando sobre o que já havia feito em Minas.

Percebe-se que a primeira estratégia do PSDB foi apenas valorizar a história do candidato e atacar o governo do PT. No programa do dia 28 de agosto, depois do narrador em off dizer "para fazer o governo funcionar, vote em que já fez funcionar", Aécio aparece no debate da Bandeirantes, criticando o país mostrado na propaganda do PT: " O que dizem hoje no Brasil a fora é que o sonho de consumo dos brasileiros é morar na propaganda do PT, onde não há inflação, não há desemprego, o crescimento é pleno".

Provavelmente, a estabilidade de Marina Silva, que se mantinha em segundo lugar nas pesquisas de intenção de voto, fez a coordenação da campanha de Aécio Neves deixar de confrontar apenas Dilma Rousseff e passar a atacar a presidenciável do PSB. No programa do dia 30 de agosto, Aécio pede ao eleitor para conversar com ele sobre "mudanças" (esse programa é repetido no dia 02 de setembro). Aécio afirma: "há quatro anos a maioria dos brasileiros elegeu a Dilma para fazer a economia crescer, manter a inflação sob controle, parar a corrupção [...] Dilma teve essa oportunidade mas o fato é que seu governo não deu certo, e hoje o país está pior que há quatro anos." O desejo de mudanças é colocado como correto, mas Aécio, implicitamente, diz ao eleitor que ele não deve errar de novo: "Tem quem ache que essa mudança é só tirar o PT do governo e o assunto está encerrado. Eu até entendo,

12 Vale lembrar que Marina Silva só entrou na disputa depois da morte de Eduardo Campos, que era o presidenciável do PSB. Em suas propagandas, Marina afirmava que ia levar adiante as ideias de Campos para o país. 
mas essa é apenas uma parte da solução, porque além de trocar aquilo que não funciona é preciso colocar no lugar um governo que funcione". A escolha de Marina seria um erro:

\begin{abstract}
Hoje, você que quer mudanças tem dois principais caminhos: a Marina e eu. Eu respeito a Marina. Ela também é uma pessoa com boas intenções, mas a gente já viu que pra mudar tudo que está errado é preciso muito mais do que isso. Para governar, para fazer acontecer, é preciso ter uma equipe sólida, ideias já testadas e, principalmente, força política para fazer a mudança acontecer de verdade. Sem experiência, sem força política, o sistema engole as boas intenções da noite pro dia. [...] Eu sei do que estou falando, porque eu já enfrentei situações como essa muitas vezes na minha vida.
\end{abstract}

Aécio oferece exemplos para confirmar o que havia sido dito: "Quando governei Minas Gerais, cortei secretarias e privilégios, para que sobrasse dinheiro para investir nas pessoas, na Saúde e na Segurança, na Educação. Sem força política, a mudança que você quer simplesmente não acontece". Depois de supostos eleitores, em estúdio, reforçarem a fala de Aécio, o jingle finaliza o recado: "A força que o Brasil precisa, chamou. Aé aé aé, Aécio, eu vou..." Efeito de sentido que se pretende gerar: só Aécio tem força para mudar o Brasil, e ele chama o eleitor para ir junto nessa mudança.

Ao adotar a nova estratégia de "partir para o ataque" à Marina Silva, o PSDB "se une" ao PT na tentativa de desconstruir a imagem de Marina, que aparecia, naquele momento, como um "fenômeno eleitoral". No programa seguinte, 04 de setembro, o candidato afirma: "mais do que fazer um programa eleitoral, eu quero conversar com você. Nós estamos a um mês das eleições. Eleições cuja decisão vai impactar muito na vida de cada um de nós. E as coisas começam a clarear".

O efeito de sentido gerado é que, com o passar dos dias que antecedem o voto na urna, o eleitor já pode ver melhor o que representa cada candidatura: "De um lado, nós temos a candidatura oficial, a candidatura do PT, que fracassou, que vai nos deixar como herança um país pior do que aquele que recebeu, com a economia encolhendo, com a inflação subindo e com a perda enorme de credibilidade." Depois da crítica ao governo do PT, passa a falar sobre os presidenciáveis que têm chance de disputar o segundo turno com Dilma: "Temos duas candidaturas no campo oposicionista. Uma é a nossa, construída a partir de debates intensos no Brasil afora, que foram muito além do nosso partido, das nossas alianças políticas, e chegaram à sociedade brasileira".

Aécio se coloca como maior que o PSDB e as ideias do partido, mostrando que seu projeto é de todo o Brasil, quase apartidário, como boa parte dos manifestantes do junho de 2013 desejavam que fossem as manifestações daquele ano. Continua seu discurso, falando sobre Marina: "Eu respeito a Marina, mas é importante que nós compreendamos de forma 
muito clara qual a Marina que está disputando estas eleições". O candidato indaga, então, ao eleitor:

\begin{abstract}
Você conhece mesmo a Marina? Eu me lembro que eu ainda líder partidário, na Câmara dos Deputados, defendi a Lei de Responsabilidade Fiscal, não para atender interesses do PSDB, mas para atender interesses dos cidadãos brasileiros, para acabar com a farra das administrações públicas irresponsáveis. Onde estava Marina? No PT, votando contra a Lei de Responsabilidade Fiscal. [...] Veio o escândalo do mensalão [...] que trouxe indignidade a toda a sociedade brasileira. Onde estava Marina? Ministra de Estado. Se indignou? Pediu pra sair? Não. Continuou como Ministra de Estado. Nos brindou com um obsequioso silêncio. Naquele momento, não considerou o mensalão práticas da velha política. [...] Vejo Marina quase como uma metamorfose ambulante, trocando de posições ao sabor das circunstâncias.
\end{abstract}

O candidato prossegue, apelando, assim como Dilma, à falta de experiência de Marina: "O Brasil pagou um preço caríssimo pela inexperiência da atual presidente da República. [...] O Brasil não merece uma nova quadra de incertezas como viveu ao longo desses últimos anos. Nosso caminho é o caminho da coerência, dos quadros qualificados, da experiência". O país de Aécio seria o da tranquilidade, da segurança. Seu jingle avisa que ele é a força que a pátria guerreira (alusão ao junho de 2013) precisa: "Um novo Brasil pra gente, decente, maduro. Caminhando diferente, pra frente, seguro. Acorda o país inteiro, avisa o povo nas ruas. Levanta Brasil guerreiro, vem junto, que a pátria é sua. A força que o Brasil precisa, chamou. Aé, aé, aé Aécio, eu vou". Depois do jingle, uma foto do candidato, narrador em off confirma: "Aécio presidente. A força que o Brasil precisa".

O programa finaliza anunciando o tema do próximo: Segurança. Dois narradores (uma mulher e um homem negro) afirmam que Aécio é a favor da redução da maioridade penal em caso de reincidência em crimes hediondos. A mulher fala que Dilma é contra; o homem afirma que Marina também.

Com o programa do dia 04 de setembro, Aécio almejava mostrar ao público que ele era a verdadeira mudança: coerente, experiente e que nunca havia sido do PT. Nas entrelinhas, o questionamento colocado ao eleitor: quem representa a mudança real, quem já esteve com o PT ou quem sempre foi contra esse partido? Se você é contra o PT, não seria mais coerente votar em que nunca foi do PT? Somando-se os ataques de Aécio aos de Dilma, estava dada a largada para que a possibilidade da polarização PT x PSDB voltasse a aparecer no horizonte da eleição de 2014. Marina passa a cair nas pesquisas, enquanto Aécio começa a subir: 
Gráfico 7- Preferência eleitoral durante o primeiro turno (\%)

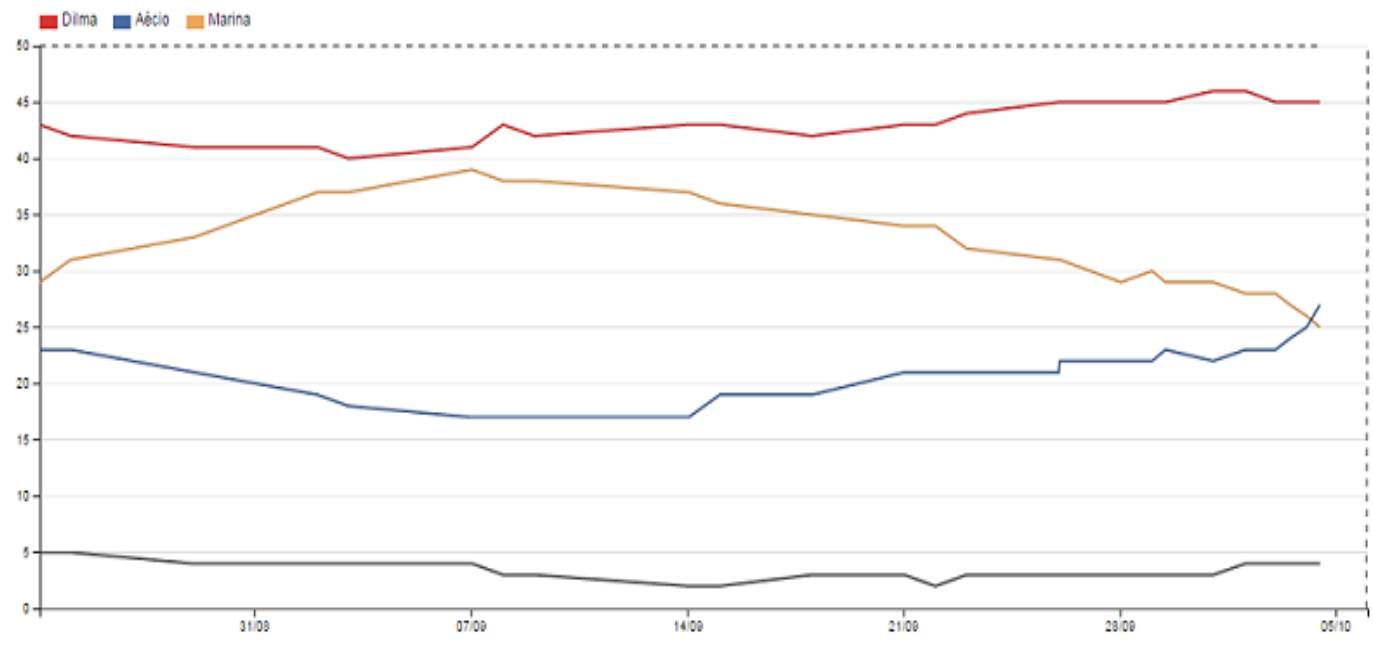

Fonte: Blog Estadão Dados (http://blog.estadaodados.com/).

Nos programas que se seguiram ao dia 04 de setembro, Aécio reforçou as críticas ao governo Dilma, reafirmando que era a oposição responsável e que sabia como fazer. No dia 11 de outubro, uma apresentadora avisa que todos falam que vão melhorar a Educação (uma das propostas de Marina era aumentar a Educação Integral), mas ninguém diz como. No governo de Aécio, Minas alcançou a melhor Educação Fundamental do Brasil. Os dados seriam do IDEB (Índice de Desenvolvimento da Educação Básica), ou seja, o próprio governo federal teria reconhecido o trabalho do Aécio em Minas. A apresentadora conclui: "essa é a mudança que dá resultado". Depois do próprio candidato falar do seu governo em Minas, o programa termina com uma comparação entre Aécio, Dilma e Marina, feita por um narrador em off:

\begin{abstract}
Marina foi ministra do governo do PT, junto com a Dilma. Enquanto isso, Aécio era da oposição e defendia mudança. Durante o escândalo do mensalão, Marina e Dilma continuaram no governo do PT. Enquanto isso, Aécio era oposição e defendia a mudança. Quando Lula escolheu Dilma para ser sua candidata, Marina saiu do PT, foi candidata pelo Partido Verde e perdeu a eleição. Marina, então, saiu do Partido Verde para criar um outro partido, a Rede. Como não conseguiu, Marina foi para o PSB, um partido que apoiou o governo do PT até alguns meses atrás. Enquanto isso, Aécio era oposição e defendia a mudança. Agora Marina e Dilma são candidatas. Dilma promete as mudanças que não fez, e, Marina, a nova política que nem sempre praticou. Enquanto isso, Aécio segue defendendo a mudança. Aécio presidente, o caminho seguro para o Brasil mudar de verdade.
\end{abstract}

O programa do dia seguinte (13/09) é iniciado com a mesma comparação entre os três candidatos. Quando ela termina, entra Aécio e critica Dilma por causa da insegurança $a^{13}$

${ }^{13}$ Dilma afirmava querer mudar a questão da Segurança Pública, que agora era de responsabilidade também dos estados. A candidata passa a dizer que quer Governo Federal e estados da federação trabalhando juntos na 
no país: "Uma das minhas maiores críticas ao governo da presidente Dilma é que ela sempre procura uma desculpa ou um culpado para justificar aquilo que ela não resolveu. [...] Tem sido assim também na segurança pública. O governo federal tem fugido de enfrentar o problema".

Dessa forma, a luta de Aécio foi, simultaneamente, duas: colocar-se no lugar de fala da oposição e tirar Marina desse lugar, afirmando ser a única oposição capaz e confiável. Comemora o sucesso da estratégia em seu programa do dia 18 de setembro. Com vozes ao fundo, simulando os gritos de junho de 2013 (o povo acordou, o povo acordou), a propaganda mostra dados da última pesquisa Ibope (apresentada ao público no dia 16 daquele mês): "Aécio foi o único que cresceu, e a diferença para Dilma no segundo turno caiu pela metade em menos de uma semana. Aécio: a força capaz de derrotar o PT e mudar de verdade". Nesse dia, sua biografia foi apresentada o relacionando a Juscelino Kubitschek e Tancredo. Aécio fala para os eleitores receosos em votar nele, que não vai tirar nenhum benefício que eles possuam, mas ampliá-los. E quem pensa em votar na Marina, ele afirma: "Tem gente dizendo que vota na Marina com medo da Dilma ganhar a eleição. Quem ganha a eleição da Dilma, quem tira o PT do governo, somos nós. [...] Eu posso fazer o melhor governo da história desse país".

\section{PT e PSDB: COMPARANDO ESTRATÉGIAS DISCURSIVAS}

PT e PSDB representavam uma disputa de vinte anos pelo executivo federal. Para ambos (porém muito mais para a candidata petista, que ocupava o lugar de fala da situação), não seria tão fácil construir discursos dentro da formação discursiva dominante da mudança. A dificuldade era maior pelo fato de a eleição contar com uma representante da terceira via, que significaria o fim da polarização PT x PSDB. Contudo, como não havia condições sociais de produção de um discurso continuísta - posto que a opinião pública deixava claro o seu desejo por transformações - as campanhas de Dilma e Aécio tentaram "encaixar" os candidatos dentro do sentimento de mudança, interdiscurso que se ancorava também no junho de 2013. A propaganda das três candidaturas principais estabeleceram uma disputa pelo sentido da mudança e Dilma e Aécio acabaram por atualizar a polarização ao desconstruir a mudança simbolizada por Marina.

As linhas discursivas principais, da campanha de Dilma Rousseff, tentaram mostrar que: ela era mais preparada para enfrentar a crise; a mudança começou com Lula; experiências

questão da Segurança, como fizeram na Copa. Isso passa a ser dito a partir da propaganda do dia 02 de setembro, da candidata Dilma. 
com o "novo" resultaram em desastres. A estratégia fazia apelo ao medo e à competência, simbolizada por Dilma. O horário eleitoral de Aécio, por sua vez, o colocou como um estadista; o representante da verdadeira mudança, já que nunca havia sido PT. Sua estratégia também mobilizava o medo, apresentando a experiência do candidato como solução diante da inexperiência e inconstância de Marina. Aécio conseguiu sua vaga no segundo turno, conquistando a confiança do eleitor. De acordo com Charaudeau:

\begin{abstract}
Separar as ideias do ethos é sempre um álibi que impede de ver que, em política, aquelas não valem senão pelo sujeito que as divulga, as exprime[...]. É preciso que este seja ao mesmo tempo crível e suporte de identificação à sua pessoa. Crível porque não há político sem que se possa crer em seu poder de fazer; suporte de identificação porque para aderir às suas ideias é preciso aderir a sua pessoa. (p.118, 2008).
\end{abstract}

Nesse sentido, infere-se que tanto Aécio como Dilma conseguiram construir imagens mais confiáveis, êxito que obtiveram ao questionar os eixos discursivos principais da campanha de Marina: mudança; alternativa à velha política; quebra da polarização. Os dois primeiros temas seriam mais fáceis de ser combatidos, mas como afirmar que uma postulante pelo PSB não quebraria a polarização entre PT e PSDB? Aécio afirmou que Marina era PT, e, Dilma, que a adversária tinha propostas piores que o PSDB. A grande profusão de ataques fez o eleitor optar por caminhos já conhecidos, atualizando a costumeira polarização.

\title{
5. CONSIDERAÇÕES FINAIS
}

Neste artigo, buscou-se trabalhar com a ideia a ascensão de candidaturas de terceira via no cenário eleitoral brasileiro e com as percepções que os eleitores dessas candidaturas têm apresentado acerca de temas como democracia e partidos políticos nacionais, combinando esses elementos com uma análise do horário eleitoral de PT e PSDB. Por meio de dados do ESEB, examinou-se como os eleitores de terceira via têm se posicionado nos últimos pleitos.

O período verificado apresentou um aumento da satisfação desses eleitores com o funcionamento da democracia. No que tange aos partidos políticos em si, foi possível perceber uma queda da identificação com esses entre 2002 e 2006, seguida por um aumento muito significativo em 2010, com a mesma tendência sendo encontrada quando tratamos da avaliação dos partidos políticos, o que demonstra, novamente, a crise institucional instaurada no ano de 2006. E quando são examinadas as posições dos entrevistados no que concerne aos dois partidos hegemônicos nas campanhas presidenciais, nota-se uma maior rejeição ao PSDB do que ao PT. 
Não obstante, é fundamental ressalvar que o cenário eleitoral de 2014 apresentou elementos que podem subverter muitas dessas tendências, a começar pela maior simpatia dos eleitores ora verificados com Partido dos Trabalhadores. Na última eleição, ocorreu grande desgaste do PT, em uma disputa acirradíssima com o PSDB, na qual Marina Silva apoiou o candidato Aécio Neves, no segundo turno, contra Dilma Rousseff. O sentimento de antipetismo, que já era bastante notável em grande parte da população nos últimos anos, exacerbou-se no pleito de 2014, o que pode ensejar uma maior possibilidade de eleitores terceira via se aproximarem do PSDB em ocasiões futuras.

Outro aspecto importante que aparece como componente que capaz de modificar algumas tendências trata-se do junho de 2013. Naquele momento, foi possível notar o crescimento de um forte apelo antipartidário e institucional, com o sentimento de revolta atingindo o PT e a presidente Dilma Rousseff. Desse modo, apesar da tendência maior de simpatia do eleitor terceira via pelos petistas, outros elementos podem sofrer mudanças de configuração em análises futuras.

Se ainda não dispomos de dados de surveys para analisar posições dos eleitores de terceira via em 2014, já foi possível, porém, do ponto de vista da análise do discurso, verificar como o campo político (especificamente, PT e PSDB) trabalhou em relação à ascensão da terceira via. Os discursos apresentados ao eleitor, através da propaganda eleitoral, iam no sentido da mobilização do imaginário dos temores, relacionados à Marina Silva: o eleitor gostaria de trocar o conhecido pelo duvidoso? E se a mudança significasse um governo ainda pior? Importante dizer que nenhum candidato se opôs à formação discursiva dominante do momento: mudança. A diferença entre Dilma, Aécio e Marina foi na construção do significado dessa mudança, com os dois primeiros conseguindo convencer o eleitorado de que, na disputa de 2014, ainda valia a pena apostar em opções já conhecidas no comando da nação. Se o desejo do eleitor era não renovar a polarização entre PT e PSDB, ele não poderia ser contemplado por Marina, que já havia sido do PT (como afirmado na propaganda de Aécio) e tinha propostas para a economia ainda mais liberais que o PSDB (de acordo com o que foi dito na propaganda de Dilma).

\section{REFERÊNCIAS}

ALMEIDA, J. 1999. Lugar de fala, polissemia e paráfrase nos discursos de FHC e Lula sobre o Plano Real. Ícone, I (4), pp. 168-202.

2004. Serra e a mudança: um discurso fora do lugar de fala. In: Antonio Albino Canelas Rubim (Org.). Eleições presidenciais em 2002 no Brasil. São Paulo: Hacker. 
BAQUERO, M. 2007. Eleições e capital social: uma análise das eleições presidenciais no Brasil (2002-2006). Opinião Pública, v. 13, n. 2, pp. 231-259.

BOURDIEU, P. 1989. O Poder Simbólico. Rio de Janeiro: Bertrand Brasil.

CHAMPAGNE, P. Formar a opinião: o novo jogo político. Rio de Janeiro: Vozes, 1998.

CERVI, E. 2014. Eleições casadas, votos solteiros e PT em namoro eleitoral com PSDB: uma descrição da tendência de polarização das eleições presidenciais entre 1994 e 2014. Em Debate, v. 6, n. 6, pp. 25-46.

CHARAUDEU, P. 2006. Discurso Político. São Paulo: Contexto.

GUGLIANO, A.; JEREZ, A. 1996. Las elecciones brasileñas de 1994: ¿continuidad o cambio?. América Latina Hoy, 13, pp. 73-79.

MANIN, B. 1995. As Metamorfoses do Governo Representativo. Revista Brasileira de Ciências Sociais, no 29, outubro de 1995.

MAINGUENEAU, D. Ethos, cenografia, incorporação. In: Ruth Amossy (Org.). Imagens de si no discurso: a construção do ethos. São Paulo: Contexto, 2005.

MARTINS, J.M.L. 2012. Política para eleitor ver: imaginários sociais e performances de Serra e Dilma no horário eleitoral de 2010. Dissertação de Mestrado, Fortaleza: UFC.

MIGUEL, L. F. 1999. Mídia e eleições: a campanha de 1998 na Rede Globo. Dados, v. 42, n. 2.

ORLANDI, E. P. 2012. Análise de discurso: princípios e procedimentos. 10 ed. São Paulo: Pontes editores.

PINTO, C. R. J. 1989. Com a palavra o senhor presidente José Sarney ou como entender os meandros da linguagem do poder. São Paulo: Hucitec. 